\title{
Stabilization and Reactions of Sulfur Radical Cations: Relevance to One-Electron Oxidation of Methionine in Peptides and Proteins
}

\author{
Krzysztof Bobrowskia ${ }^{a}$ Chantal Houée-Levin ${ }^{\star}$, and Bronislaw Marciniak ${ }^{c}$
}

\begin{abstract}
Methionine is a key amino acid that has numerous roles in essential vital processes. Moreover, methionine oxidation is biologically important during conditions of oxidative stress and represents an important step in the development of some severe pathologies. Considerable work has been performed to understand the mechanisms of one-electron oxidation of the Met-residue as a function of its proteic environment. The most important recent results obtained by means of time-resolved techniques (laser flash photolysis and pulse radiolysis) on model peptides containing single or multiple Met-residues and in selected naturally occurring peptides (Met-enkephalin and $\beta$-amyloid peptide) and proteins (thioredoxin and calmodulin) have been reviewed.
\end{abstract}

Keywords: Flash photolysis · Gamma and pulse radiolysis · Methionine .

One-electron oxidation of peptides and proteins $\cdot$ Two-center-three-electron bonds

\section{Introduction}

Methionine (Met) (Fig. 1) is an essential amino acid that should be provided by food. It has numerous fundamental roles in biochemistry, ranging from protein synthesis in ribosomes to involvement in reactions of methylation that are essential to life ${ }^{[1]}$ or to the regulation of the lifetime of proteins in cells.[2] Among the amino acid residues normally found in the proteins, Met is one of the most readily oxidized. The thioether

${ }^{*}$ Correspondence: Prof. C. Houée-Levin ${ }^{\mathrm{b}}$

Tel.: +33169155549

Fax: +33169156188

E-mail: chantal.houee@u-psud.fr

alnstitute of Nuclear Chemistry and Technology

Dorodna 16, 03-195 Warszawa, Poland

bLaboratoire de Chimie Physique

UMR 8000 Université Paris Sud

F-91405 Orsay, France

cFaculty of Chemistry

Adam Mickiewicz University

Grunwaldzka 6, 60-780 Poznań, Poland

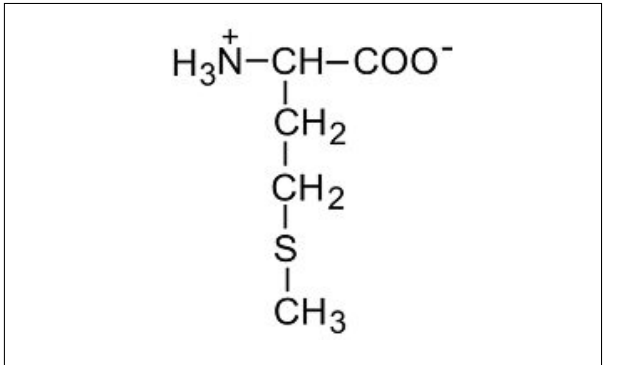

Fig. 1. The structure of methionine

function present in the side chain of Met is susceptible to attack by oxygen or nitrogen free radicals. The redox reactions of Met or of its derivatives due to its thioether function are important in the cellular life. The sulfur function is susceptible to attack by oxygen or nitrogen free radicals. ${ }^{3]}$

Two major pathways of Met oxidation can be recognized, one- and two-electron oxidation. ${ }^{[4]}$ Methionine two-electron oxidation leads frequently to methionine sulfoxide ( $\mathrm{R}-\mathrm{SOCH}_{3}$, abbreviated MetSO), which is a relatively commonly detected oxidative modification in biological systems. This oxidation could play a role in redox homeostasis, prevention of irreversible modifications, pathogenesis, and the aging process. ${ }^{[5]}$ Methionine sulfoxide reductase can regenerate Met, thus this amino acid could act as a molecular switch to detoxify oxidants and protect important regions of the protein. ${ }^{[6]}$ Therefore, this amino acid may act as a 'last chance antioxidant' in the defence system of proteins by detoxification of oxidants and by protection of important regions of the protein. Moreover, oxidation of Met is also a serious damaging event associated with neurotoxicity ${ }^{[7-9]}$ and a major cause of the functional impairment of actin filaments, ${ }^{[10]}$ and may be responsible for other specific disease states, such as JacobCreutzfeld's syndrome and Parkinson's disease. [11] The redox reactions of Met or its derivatives are important in cellular life. The one-electron oxidation of Met yields highly unstable sulfide radical cations (Met>S $\mathrm{S}^{\bullet+}$ ), which can further convert irreversibly to a series of products. Various biologically relevant reactive oxygen species (ROS) react with Met via one-electron oxidation and therefore may modify proteins containing Met residues irreversibly.[4,12,13]

The oxidation of Met by strong oneelectron oxidants such as triplet benzophenone derivatives, ${ }^{114]} \mathrm{X}_{2}{ }^{\bullet-}(\mathrm{X}=\mathrm{Cl}, \mathrm{Br}, \mathrm{I}),{ }^{[15]}$ $\mathrm{CCl}_{3} \mathrm{OO}^{\bullet},{ }^{[16]} \mathrm{Tl}^{2+}{ }_{[17]}$ and the hydroxyl radicals $\left({ }^{\bullet} \mathrm{OH}\right)$ has been found to yield Met $>\mathrm{S}^{\bullet+}$ radical cations and hydroxysulfuranyl radicals $\left(\mathrm{Met}>\mathrm{S}^{\bullet}-\mathrm{OH}\right),{ }^{[18]}$ respectively. Neighboring group participation is an important concept for understanding how the intermediate moiety formed at the sulfide site affects the ultimate course of the Met oxidation. ${ }^{[19]}$ These neighboring groups can provide a lone pair of electrons which can 
be shared with the Met $>\mathrm{S}^{\bullet+}$ radical actions, forming two-center-three-electron (2c-3e) bonds which effectively stabilize the radical.[20] This occurs through the overlap of the heteroatoms' doubly occupied p orbitals with the singly occupied $\mathrm{p}$ orbital of the sulfur and the resulting bond is a threeelectron bond of the type $2 \sigma / 1 \sigma^{*}$. $^{[21,22]}$ The same applies to the Met $>\mathrm{S}^{\bullet}-\mathrm{OH}$ radicals, but their subsequent reactions might be different since they are strongly affected by the presence of neighboring groups.

Effects of neighboring groups on the reactions of these two intermediates, Met $>\mathrm{S}^{\bullet+}$ and Met $>\mathrm{S}^{\bullet}-\mathrm{OH}$ with particular peptide or protein domains may be of great importance since in peptides and proteins, Met residues are potentially surrounded by a variety of neighboring groups such as carboxylate, amino, hydroxyl, and amide functionalities. Several studies were devoted to the experimental[23] and theoretical characterization ${ }^{[24]}$ of the resulting $\mathrm{S} \therefore \mathrm{X}$ bonds $(\mathrm{X}=\mathrm{S}, \mathrm{N}$, and $\mathrm{O})$. Until recently, evidence for stabilization of sulfur radical cations in peptides came mainly from the lone pairs of electrons on the $\mathrm{C}$-terminal and $\mathrm{N}$-terminal moieties of the peptides.[25,26] Such complexation increases the lifetime of the oxidized sulfur center, modifies its reduction potential and hence its reactivity. On the other hand, the electron lone pairs on the heteroatoms in peptides bonds were considered to be too delocalized throughout the amide/ carbonyl moiety to be able to participate in the bonding with the unpaired electron on Met $>S^{\bullet+}$. However, frequently heteroatoms, either the carbonyl oxygen atom or the amide nitrogen atom, in peptide bonds are the only nucleophiles present in the vicinity of Met $>\mathrm{S}^{\bullet+}$. Information on whether Met $>\mathrm{S}^{\bullet+}$ can also be stabilized by bonding to the heteroatoms involved in peptide bonds is important since such stabilization might potentially facilitate oxidation and auto-oxidation processes in peptides and proteins containing Met residues.

Observation of such free-radical processes in real biological systems is currently difficult to unravel because of the complexity of the chemical environment and the availability of the biological material. Therefore, an attempt has been made to isolate some of the mechanistic steps during ${ }^{\bullet} \mathrm{OH}$-induced oxidation of model and natural peptides and proteins containing Met residues.

In this mini-review article an overview over the very recent experimental studies performed or being performing currently mostly in three research groups from France and Poland. They are involved in the COST Action CM0603 'Free Radicals in Chemical Biology' supported by ESF and launched in 2007. These studies were aimed at the kinetic and spectral character- ization of the $\mathrm{S} \therefore \mathrm{X}$-bonded species generated radiolytically (by pulse radiolysis) or photochemically (by laser flash photolysis) in model peptides containing single or multiple Met-residues and in selected naturally occurring peptides (Met-enkephalin and $\beta$-amyloid peptide) and proteins (thioredoxin and calmodulin). To get closer to biological problems, the oxidation was studied in peptides and proteins, with the characterization of the final products.

\section{Experimental}

\subsection{Radiolysis}

\subsubsection{Radiolysis of Water}

Radiolysis of water leads to the formation of three primary reactive transients represented as reaction 1 . In addition, stable products, $\mathrm{H}_{2}, \mathrm{H}_{2} \mathrm{O}_{2}$ and $\mathrm{H}_{3} \mathrm{O}^{+}$are formed.[27]

$\mathrm{H}_{2} \mathrm{O} \rightarrow \mathrm{e}^{-}$aq $\left.(0.28),{ }^{\bullet} \mathrm{H}(0.062),{ }^{\bullet} \mathrm{OH} 0.28\right)$, $\mathrm{H}_{2}(0.047), \mathrm{H}_{2} \mathrm{O}_{2}(0.073), \mathrm{H}_{3} \mathrm{O}^{+}(0.28)$

The numbers in brackets are the radiation chemical yields (known as $G$-values) in units $\mu \mathrm{M} \mathrm{J}^{-1}$. In the early literature $G$ values were expressed as number of molecules $/ 100 \mathrm{eV}$. The conversion factor is: 1 molecule $/ 100 \mathrm{eV}=1.036 \times 10^{-7} \mathrm{~mol} \mathrm{~J}^{-1}$.

In $\mathrm{N}_{2} \mathrm{O}$-saturated solutions $\left(\left[\mathrm{N}_{2} \mathrm{O}\right] \approx 2 \times\right.$ $10^{-2} \mathrm{~mol} \mathrm{~J}^{-1}$ ), the hydrated electrons, $\mathrm{e}^{-}$aq are converted into ${ }^{\circ} \mathrm{OH}$ radicals according to reaction $2\left(\mathrm{k}_{2}=9.1 \times 10^{9} \mathrm{M}^{-1} \mathrm{~s}^{-1}\right)$. [28] Reaction 2 nearly doubles the amount of - OH radicals available for reactions with substrates.

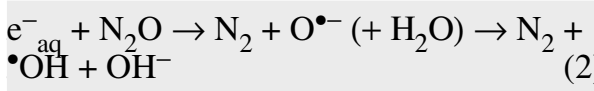

At $\mathrm{pH}<4$ the diffusion-controlled reaction of $\mathrm{e}^{-}$aq with protons becomes important (reaction $3, k_{3}=2.0 \times 10^{10} \mathrm{M}^{-1} \mathrm{~s}^{-1}$ ) ${ }^{[29]}$ resulting in a $\mathrm{pH}$-dependent lowered yield of $\bullet \mathrm{OH}$ radicals and a correspondingly increased yield of ${ }^{\bullet} \mathrm{H}$ atoms.

$$
\mathrm{e}^{-}{ }_{\mathrm{aq}}+\mathrm{H}^{+} \rightarrow{ }^{\bullet} \mathrm{H}
$$

The effective radiation chemical yields $(G)$ of the primary species available for the reaction with a substrate depend on the concentration of the added substrate. For $\mathrm{N}_{2} \mathrm{O}$ saturated solutions, the effective radiation chemical yield of ${ }^{\bullet} \mathrm{OH}$ radicals converting a given substrate into substrate-derived radical can be calculated on the basis of formula given by Schuler et al. ${ }^{[30]}$ The initial reaction of hydroxyl radicals $\left({ }^{\bullet} \mathrm{OH}\right)$ with substrates containing thioether group leads to the formation of hydroxysulfuranyl radical (reaction 4).[30]

$\bullet \mathrm{OH}+>\mathrm{S} \rightarrow>\mathrm{S}^{\bullet}-\mathrm{OH}$
Depending on the $\mathrm{pH}$, the concentration of substrate, and the presence of neighboring groups in the molecule of substrate the subsequent reactions of the hydroxysulfuranyl radical $>\mathrm{S}^{\bullet} \mathrm{OH}$ are different.

\subsubsection{Pulse Radiolysis}

Any technique for a direct study of fast free radical reactions must be characterized by a short time of generation of free radicals and simultaneously comprise of a correspondingly fast detection system. ${ }^{[31]}$ It is highly desirable that the formation of the radical is completed within a time period that is short compared to the lifetime of the radical. Furthermore, the radical must exhibit a 'detectable property'. In this respect, the most frequently used 'properties' in measurements are: optical absorbance (in UV, Vis and IR regions) ${ }^{[32]}$ and conductance. ${ }^{[33]}$ Due to the instability of radicals in solution, fast time-resolved techniques (pulse radiolysis, PR) are the premiere tools to obtain thermodynamic, kinetic and spectral properties of radicals. Generation of radicals is achieved by admitting short pulses of high-energy electrons $(\mathrm{MeV}$ range) generated in accelerators. In PR with optical detection and/or conductance detection the formation of the radicals and their subsequent reactions are then monitored by the change in the transmitted light intensity through the reaction cell as a function of time using monochromator and suitable photodetectors or by the change of the conductance as a function of time. The detector converts changes in the analyzing light intensity or the conductance into electrical analog signals. These signals are digitized, displayed and stored in the digitized oscilloscope, and are subsequently transferred to the computer for further processing.

Pulse radiolysis experiments were performed on three different linear electron accelerators, the $8 \mathrm{MeV}$ Titan Beta model TBS 8/16-1 electron accelerator at the Radiation Laboratory (USA) and the $10 \mathrm{MeV}$ LAE10 electron accelerator at the Institute of Nuclear Chemistry and Technology (Poland) (details in ref. [34]) and the linear accelerator of the Curie Institute in Orsay (France) (details in ref. [35]).

\subsection{Photochemistry}

\subsubsection{Photogeneration of the Triplet} State and Sensitized Photooxidation

The oxidation of organic compounds containing the thioether group can occur via sensitized photooxidation, in addition to the previously described radiation-induced reactions. In this case, after the initial absorption of incident light by a sensitizer (absorption to singlet excited states), followed by an efficient intersystem crossing process (a radiationless process within the sensitizer), the triplet excited state is formed (Fig. 2). 


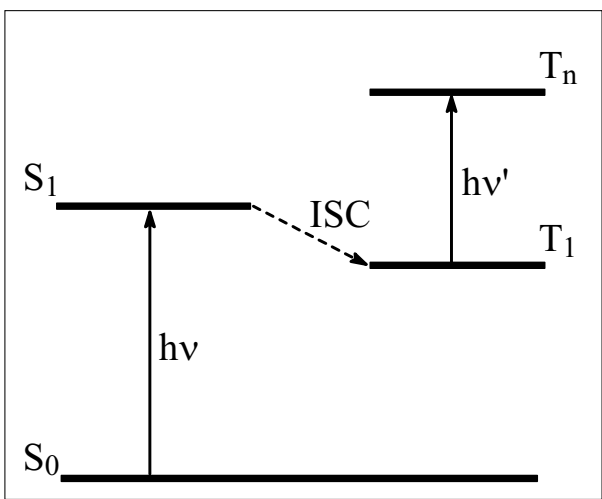

Fig. 2. Energy level diagram (Jablonski diagram) of sensitizer $\left(S_{0}, S_{1}\right.$ represent ground and lowest excited singlet states, $T_{1}$ - lowest excited triplet state, and $\mathrm{T}_{\mathrm{n}}$ - higher excited triplet state). ISC: intersystem crossing.

The sensitizer molecule in its lowest excited triplet state can be used as a strong one-electron oxidant. Water-soluble 4-carboxybenzophenone (CB) is a good photosensitizer for this type of reactions due to its spectral, photophysical and electrochemical properties. In addition, the transient absorption spectra of the $\mathrm{CB}$ triplet $\left(\mathrm{T}_{1}-\mathrm{T}_{\mathrm{n}}\right.$ transition, Fig. 2), the $\mathrm{CB}$ radical anion $\left(\mathrm{CB}^{\bullet-}\right)$, and the ketyl radical $\left(\mathrm{CBH}^{\bullet}\right)$ together with their molar absorption coefficients are well described in the literature[36] and can be used as reference spectra.

The CB-sensitized photooxidation of substrates containing thioether groups $(>S)$ leads to formation of the $\mathrm{CB}^{\mathrm{c}-}$ radical anion and the $>\mathrm{S}^{\bullet+}$ radical cation:

${ }^{3} \mathrm{CB}^{*}+>\mathrm{S} \rightarrow \mathrm{CB}^{\bullet-}+>\mathrm{S}^{\bullet+}$

However, the general mechanism of sensitized photooxidation is more complex (Scheme 1). The quenching of the excited triplet state of CB leads to the formation of the short-lived radical ion pair. There are three main channels of its decay:

i) back electron transfer to form the reactants in their ground states,

ii) proton transfer within the radical ion pair to form the ketyl radical and an $\alpha$ alkyl thioalkyl radical, and

iii) escape of ion radicals to form $\mathrm{CB}^{\bullet-}$ and the sulfur-centered radical cation $\left(>S^{\bullet+}\right)$. Yields of the primary reactions depend on the solvent used, the $\mathrm{pH}$ and the structure of the quencher.[37,38]

\subsubsection{Laser Flash Photolysis}

Free radicals and radical ions formed in photochemical reactions can be detected using nanosecond laser flash photolysis. In principle this method is similar to the pulse radiolysis technique previously described. The main difference is in the radical generation. Instead of using high energy electrons from accelerators to produce the radicals, the laser light is used in the flash photoly-

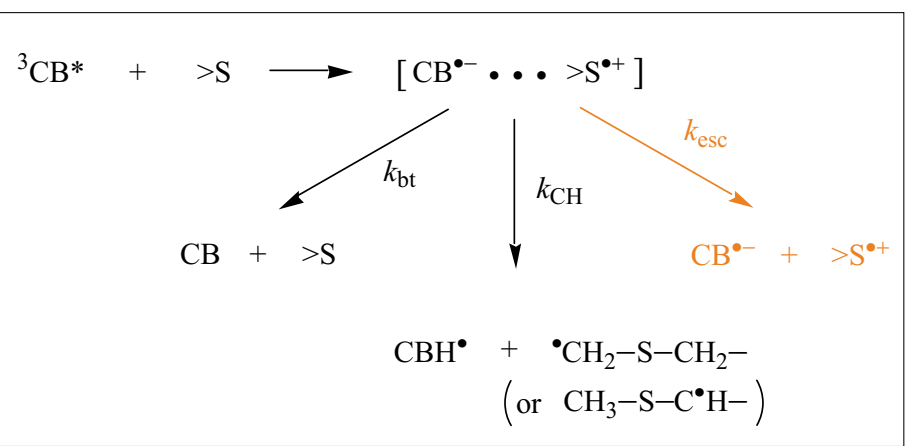

Scheme 1. Primary photochemical processes of photosensitized oxidation of thioethers by a water-soluble 4-carboxybenzophenone (CB)

sis systems. The simplified scheme of the nanosecond laser flash photolysis setup is presented in Fig. 3. ${ }^{[39]}$

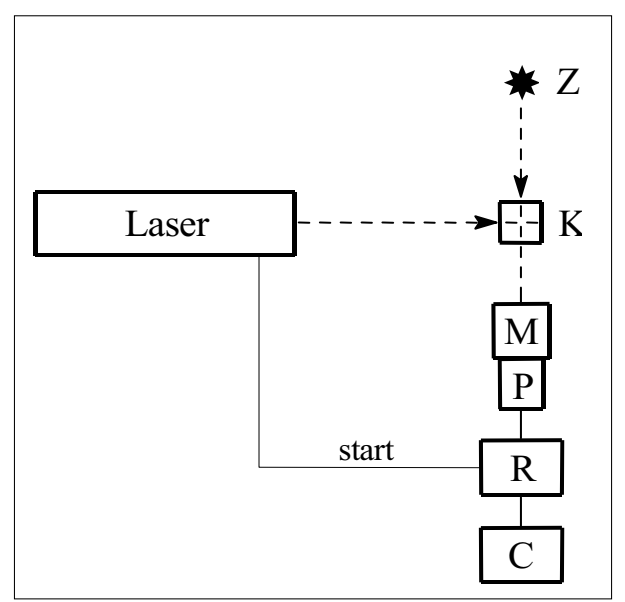

Fig. 3. Simplified scheme of a nanosecond laser flash photolysis setup $(Z=$ xenon lamp, $\mathrm{K}=$ reaction cell, $\mathrm{M}=$ monochromator, $\mathrm{P}=$ photomultiplier, $\mathrm{R}=$ oscilloscope, $\mathrm{C}=$ computer)

This apparatus allows the experimentalist to measure i) transient absorption spectra at various delay times after the initiating laser pulse and ii) changes of absorbance with time, measured at particular wavelengths (these curves may describe kinetic traces for formation and decay of transients). In the case where some transients absorb in the same spectral region, the procedure of resolving transient spectra into components was used.[26] This allowed us to obtain concentration profiles of all the transients and to determine the initial quantum yields of radical formation.

Two different nanosecond laser flash photolysis systems were used for the timeresolved experiments. The first apparatus (at the Notre Dame Radiation Laboratory) and its data-acquisition system have previously been described in detail..40] A nitrogen laser (Lambda-Physics) provided $8 \mathrm{~ns}$, $6 \mathrm{~mJ}$ pulses at $337 \mathrm{~nm}$. The transients were monitored with a pulsed $1 \mathrm{~kW}$ xenon lamp, having the monitoring beam perpendicular to the laser beam. A $500 \mathrm{MHz}$ LeCroy 7200
Precision Digital Oscilloscope (7242 B) was used for collecting the data. The second nanosecond laser flash photolysis system used (at Adam Mickiewicz University) consists of a Nd:YAG laser from Spectra Physics, model INDI 40-10, equipped with a harmonic generation module to achieve 266, 355 and 532 $\mathrm{nm}$ excitation wavelengths (pulses with a full width at half maximum of $c a .7 \mathrm{~ns}$ ), a detection system consisting of a pulsed xenon lamp Applied Photophysics (150 W), a monochromator from Acton, model Spectra Pro SP2155, and photomultiplier tube (Hamamatsu R955), as the monitoring source. The signal from the photomultiplier was processed by a real-time digital oscilloscope from LeCroy, model Wave Runner 6100A (1GHz, 10GS/s) and computer equipped with DAQ and timer PCI cards from National Instruments (software based on LabView 8.0).

All experiments were carried out with rectangular quartz optical cells $(0.5 \times 1$ $\mathrm{cm})$ or $(1 \times 1 \mathrm{~cm})$. Samples were deoxygenated by flushing with analytical grade nitrogen in a circulating flow-system for 20 min prior to and kept under nitrogen during measurements.

\section{Results}

\subsection{Gamma and Pulse Radiolysis}

3.1.1. Linear Oligopeptides Containing a Single Met Residue[41]

Nanosecond pulse radiolysis studies with UV/Vis spectrophotometrical and conductometric detection were performed in model peptides containing a single Met residue, N-Ac-Gly-(Gly) $)_{n-1}$-Met-(Gly) $)_{n}$ A complete mechanistic study of the redox processes of Met incorporated in peptides was provided by

i) characterization of the parameters controlling the assistance of the peptide bond in the one-electron oxidation of Met to Met $>\mathrm{S}^{\bullet+}$

ii) subsequent reactions of $\mathrm{Met}>\mathrm{S}^{\bullet}-\mathrm{OH}$ and $\mathrm{Met}>\mathrm{S}^{\bullet+}$,

iii) a novel pathway for the formation of carbon-centered radicals at the ${ }^{\alpha} \mathrm{C}$ position of Met, and 


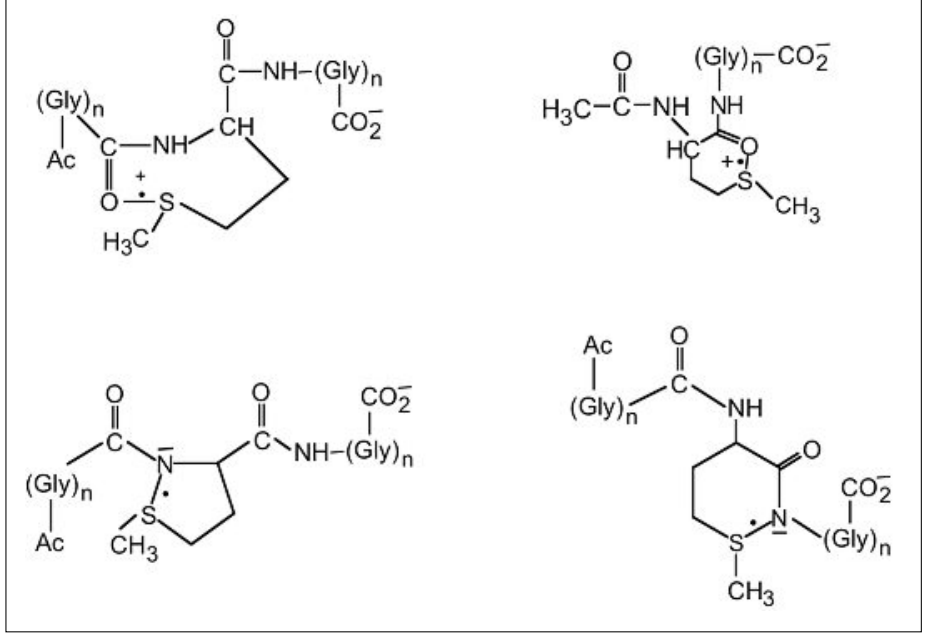

Fig. 4. Structures of the intramolecularly $\mathrm{S} \therefore \mathrm{O}$ - and $\mathrm{S} \therefore \mathrm{N}$-bonded radical cations and radicals derived from the N-Ac-Gly-(Gly $)_{n-1}$-Met-(Gly $)_{n}(n=1$, 3) linear peptides

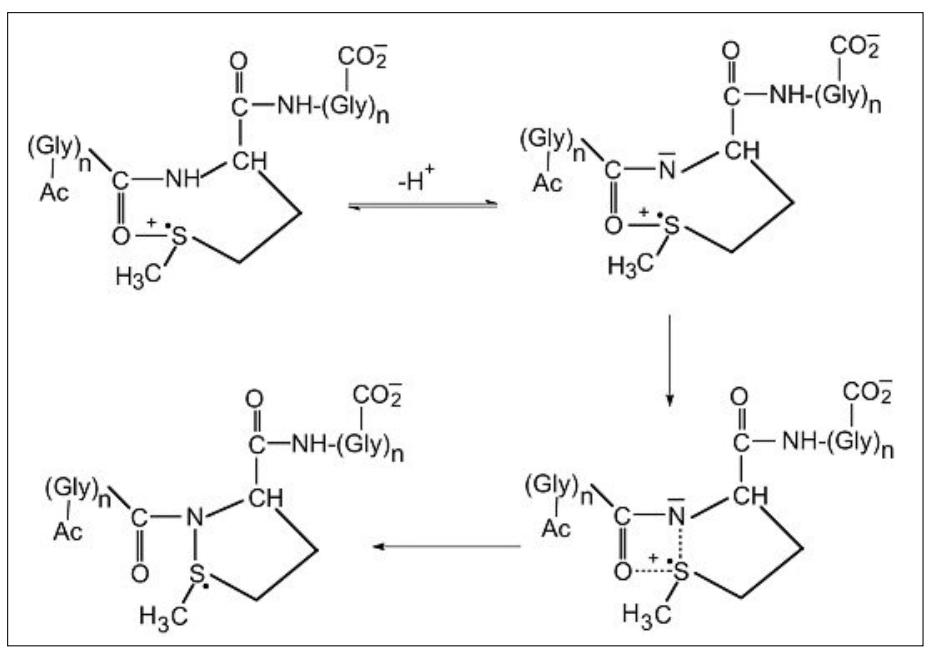

Scheme 2. The mechanism of intramolecular conversion of S:O-bonded radical cations into $\mathrm{S} \therefore \mathrm{N}$-bonded radicals iv) examination of the potential reactivity of Met $>\mathrm{S}^{\bullet+}$ toward the ${ }^{\alpha} \mathrm{C}-\mathrm{H}$ bond of adjacent Gly residues.

These studies showed for the first time that

i) Met $>\mathrm{S}^{\bullet+}$ can be stabilized intramolecularly through bond formation with either oxygen or the nitrogen atoms of adjacent peptide bonds (Fig. 4),

ii) the formation of the transients with intramolecular S $\therefore$ O-bonds is kinetically preferred, but on longer time scales; transients with $\mathrm{S} \therefore \mathrm{O}$-bonds convert into the transients with intramolecular $\mathrm{S} \therefore \mathrm{N}$-bonds in a $\mathrm{pH}$ dependent manner (Scheme 2),

iii) the ratio of intramolecularly $\mathrm{S} \therefore \mathrm{N}$ bonded species $v s$ intermolecularly $\mathrm{S} \therefore$ S-bonded species increases with increasing peptide size,

iv) the transients with intramolecular $\mathrm{S} \therefore \mathrm{N}$-bonds transform intramolecularly into $\mathrm{C}$-centered radicals located on the ${ }^{\alpha} \mathrm{C}$ moiety of the peptide backbone. Another type of C-centered radicals, located in the side chain of Met residue, is formed via deprotonation of Met $>\mathrm{S}^{\bullet+}$.

\subsubsection{S-Methylglutathione (S-MeGlu) and $\gamma$-Glu-Met-Gly Tripeptides[42]}

Neighboring group participation in stabilization of sulfur-centered radical cations $>\mathrm{S}^{\bullet+}$ was investigated in the ${ }^{\bullet} \mathrm{OH}$-induced oxidation of S-methylglutathione $(\gamma$-Glu(S-Me-Cys)-Gly) in aqueous solution by means of nanosecond pulse radiolysis. These studies provided further evidence for the intermediates formed through the intramolecular association between a sulfur radical cation $\mathrm{S}-\mathrm{Me}-\mathrm{Cys}>\mathrm{S}^{\bullet+}$ and $\mathrm{N}$ atom or O-atom in a peptide bond (Fig. 4). The $(\mathrm{S} \therefore \mathrm{O})^{+}$-bonded intermediate exists in an equilibrium with the intermolecularly $\mathrm{S} \therefore \mathrm{S}$-bonded radical cations. The short- lived $\left[>\mathrm{S} \therefore \mathrm{NH}_{2}\right]^{+}$intermediate is a precursor of decarboxylation that leads to reducing $\mathrm{C}$-centered $\alpha$-aminoalkyl-type radicals (Scheme 3).

Additional insight into the details of the sulfur radical cations' association with $\mathrm{O}$-atoms of the peptide bonds was gained by comparing the behavior of the S-MeGlu with the tripeptide $\gamma$-Glu-Met-Gly (Fig. 5).

The purpose of replacing the S-methylcysteine with methionine was to investigate the rate of ring formation involving the $\mathrm{S} \therefore \mathrm{O}$-bond formation in the respective centered-centered radical cations. With $\mathrm{S}$ MeGlu, it is possible to form five- or sixmembered rings involving the sulfur radical cation bonding with the electron pair of the oxygen atoms in the two peptide bonds on either side of it. However, with the extra methylene group in the side chain of Met, only six- or seven-membered rings can be formed through bonding of the Met $>S^{\bullet+}$ with the pair of electrons on the oxygen atoms of the adjacent peptide bonds. Experimental observations indicates that the six- or seven-membered rings containing the $(\mathrm{S} \therefore \mathrm{O})^{+}$moiety do not form efficiently enough and thus show strong preference for five- or six-membered ring configuration in the formation of intramolecularly $(\mathrm{S} \therefore \mathrm{O})^{+}-$ bonded species.

\subsubsection{Cyclic Peptides[43]}

In order to define the potential reactions of Met $>S^{\bullet+}$ in oligopeptides and proteins containing multiple and adjacent Met residues (e.g. prion proteins PrP, calmodulin $\mathrm{CaM}$ ), an attempt was made to isolate some of the mechanistic steps during ${ }^{\bullet} \mathrm{OH}$-induced oxidation of two cyclic dipeptides: $c$-(L-MetL-Met) and $c$-(D-Met-L-Met) (Fig. 6).

Cyclic dipeptides are suitable model compounds to study peptide free radical chemistry. While appearing very small to be models for proteins, they have the unique feature of having no terminal groups. This

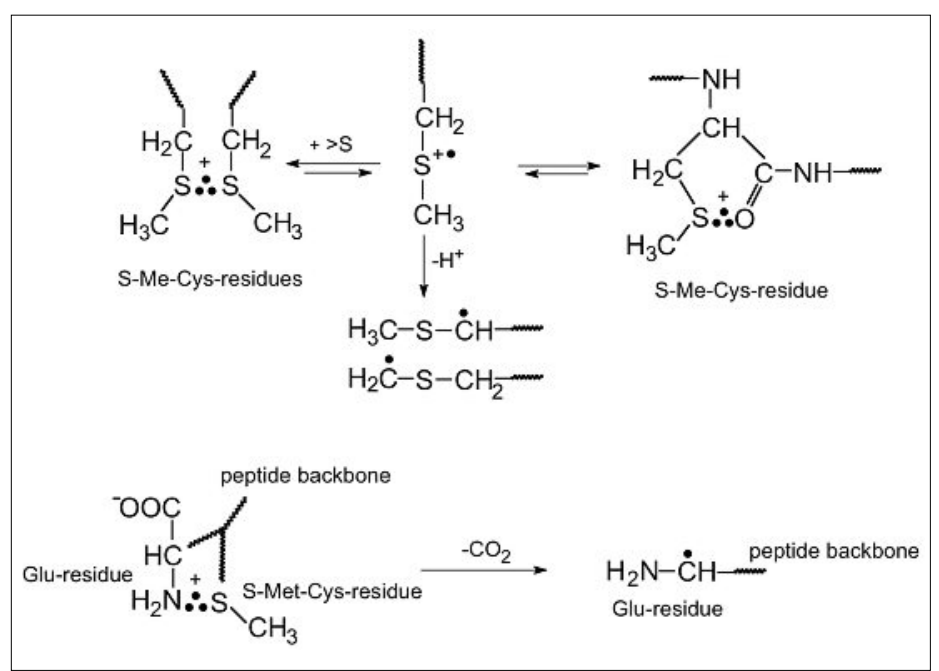

Scheme 3. Mechanisms of interconversion of sulfur radicals as a function of the neighboring groups 


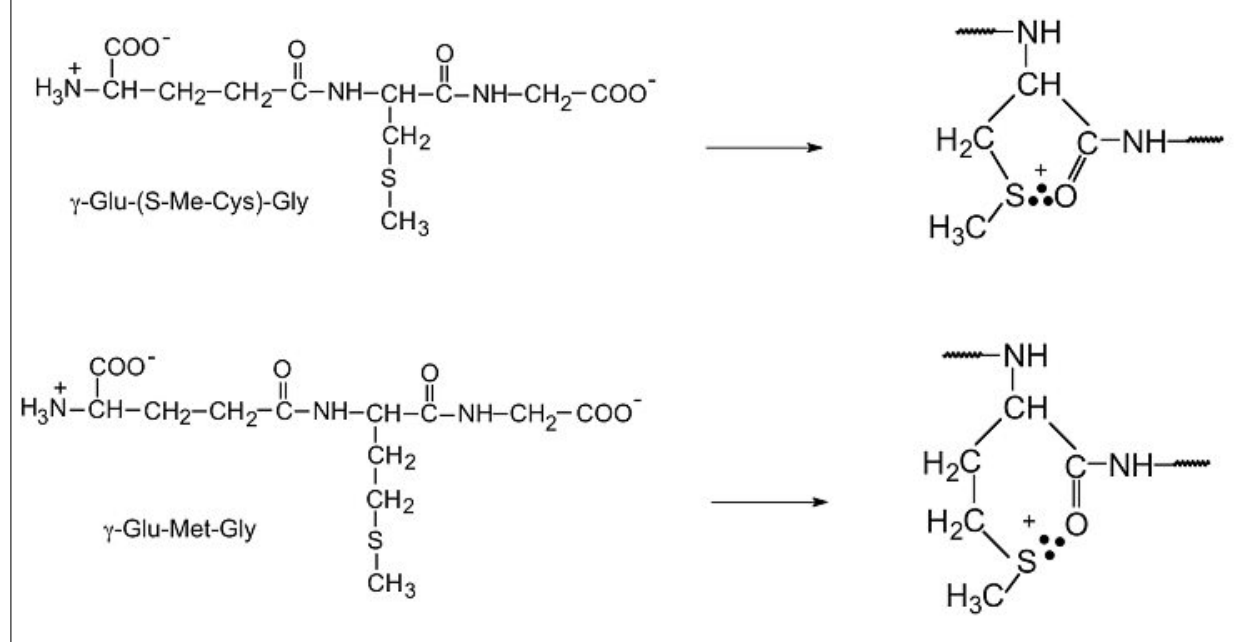

Fig. 5. Structures of the tripeptides S-MeGlu and $\gamma$-Glu-Met-Gly and the respective S.:O radicals formed from them

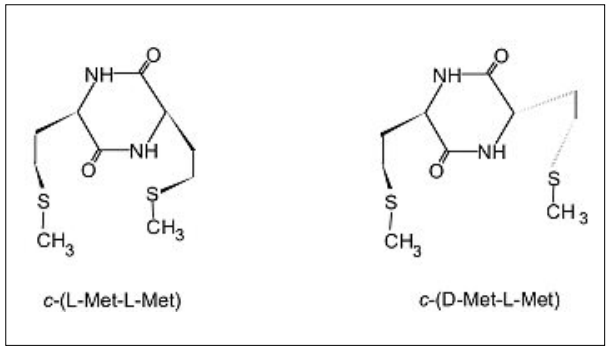

Fig. 6. Structures of the cyclic dipeptides: $c-(L-$ Met-L-Met) and c-(D-Met-L-Met)

makes them invaluable for studying interactions between side chains and peptide bonds. Moreover, changing the configuration of one Met residue from $L$ - to D- in cyclic dipeptides forces the side chains of Met residues to point in the opposite directions of the diketopiperazine ring, which makes it more difficult for them to be in close contact. The picture that emerges from these studies shows there is an efficient formation of $\operatorname{Met}(\mathrm{S} \therefore \mathrm{N})$ radicals in $c$-(L-Met-L-Met) in spite of the close proximity of two sulfur atoms, located in the side chains of methionine residues, and in spite of the close proximity of sulfur atoms and oxygen atoms located in the peptide bonds. Moreover, the formation of $\operatorname{Met}(\mathrm{S} \therefore \mathrm{N})$ radicals can proceed directly via $\mathrm{H}^{+}$-transfer with the involvement of hydrogen from the peptide bond to an intermediary hydroxysulfuranyl radical (Scheme 4).

These $\operatorname{Met}(\mathrm{S} \therefore \mathrm{N})$ radicals decay via two different $\mathrm{pH}$-dependent mechanisms. At low $\mathrm{pH}, \operatorname{Met}(\mathrm{S} \therefore \mathrm{N})$ radicals convert efficiently into intramolecular $\operatorname{Met}(\mathrm{S} \therefore \mathrm{S})^{+}$ radical cations, at a $\mathrm{pH}$ close to neutral by a hydrolytic cleavage of the protonated $\operatorname{Met}(\mathrm{S} \therefore \mathrm{NH})^{+}$, followed by electron transfer and decarboxylation.

Little or no intramolecular stabilization by the unoxidized sulfur in the neighboring Met occurs in $c$-(D-Met-L-Met), in contrast to the previously observed intramolecular

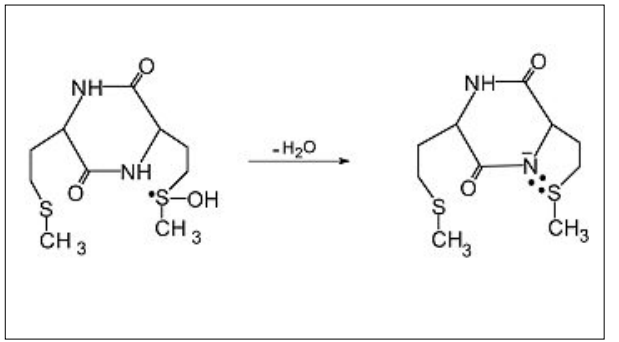

Scheme 4. The mechanism of formation of the Met(S: N) radicals

sulfur stabilization of the sulfur radical cation in the isomer $c$-(L-Met-L-Met). As with $c$-(L-Met-L-Met), sulfur radical cations $\left(>S^{\bullet+}\right)$ were found to be stabilized by bonding to the amide nitrogen atoms. This oxidation pattern observed in $c$-(D-Met-LMet) was confirmed using the oxidation of $c$-(Gly-L-Met), which has no chance for intramolecular stabilization of the sulfur radical cations.

These observations have implications for the recent pulse radiolysis experiments on the oxidation of calmodulin. No $\operatorname{Met}(\mathrm{S} \therefore \mathrm{S})^{+}$radical cations were found following the $\mathrm{OH}$-induced oxidation of calmodulin even though there are multiple Met residues, including two pairs of adjacent Met residues. Instead, stabilization of the resulting radical cation by the amide nitrogen atom was observed. ${ }^{[4]}$ These findings illustrate that these cyclic dipeptides are convenient models for projecting what might happen in proteins.

\subsubsection{Polypeptides and Proteins}

The situation is much more complex in peptides and proteins. First, methionine is not the only target of oxidizing radicals, and the absorption spectra of the sulfur radicals may be hidden by those derived from other residues such as the tyrosyl radical (TyrO`), which absorbs in the same region. ${ }^{[45]} \mathrm{Sec}-$ ond, oxidation of a residue may be followed by a long-range intramolecular electron transfer, which can be a very fast process, not rate determining. ${ }^{[46]}$ Thus, a very powerful possibility is to use continuous gamma radiolysis, which allows identification of final compounds by methods like mass spectrometry or various spectrometric methods. Up to now, oxidized methionine appeared only as MetSO and Raman spectrometry is a powerful tool to detect it.[47]

Several studies were performed using azide radicals $\left(\mathrm{N}_{3}{ }^{\bullet}\right)$, formed by oxidation of azide ions $\left(\mathrm{N}_{3}^{-}\right)$by the primary hydroxyl radicals $\left({ }^{\bullet} \mathrm{OH}\right)$

$\bullet \mathrm{OH}+\mathrm{N}_{3}^{-} \rightarrow \mathrm{OH}^{-}+\mathrm{N}_{3} \cdot$

In principle, methionine should not be oxidized by $\mathrm{N}_{3} \cdot$ radicals because the reduction potential of the $\mathrm{N}_{3}{ }^{\circ} / \mathrm{N}_{3}{ }^{-}$couple should be higher. ${ }^{[48]}$

Thioredoxin contains only one Met residue. The study of its oxidation by pulse radiolysis indicated the formation of a sulfur centered radical probably complexed to a nitrogen atom. ${ }^{[49]}$ However at the end of the process, no oxidized form of methionine in this protein could be detected. One hypothesis would be that an intramolecular electron transfer took place, from a Tyr residue to a Met-derived radical. Such electron migration has already been postulated.[46] Conversely, in $\beta$-amyloid peptide, which also contains Met and Tyr residues, only the Met residue was oxidized by $\mathrm{N}_{3}{ }^{\bullet}$ radicals, leading to MetSO. ${ }^{[47]}$ In methionine enkephalin (Met-enk) (Fig. 7), only a Tyr residue was oxidized by $\mathrm{N}_{3} \cdot$ radicals. [50] However in the presence of oxygen, traces of MetSO appeared when the amine function of the peptide was blocked. It seems that the processes and their modulation are far from being understood.

In pulse radiolysis experiments on the oxidation of calmodulin by ${ }^{\bullet} \mathrm{OH}$ radicals, no $\operatorname{Met}(\mathrm{S} \therefore \mathrm{S})^{+}$radical cations were found even though there are multiple Met residues, including two pairs of adjacent Met residues. Instead, stabilization of the resulting radical cation by the amide nitrogen atom was observed, ${ }^{[51]}$ like in cyclic peptides. ${ }^{[43]}$

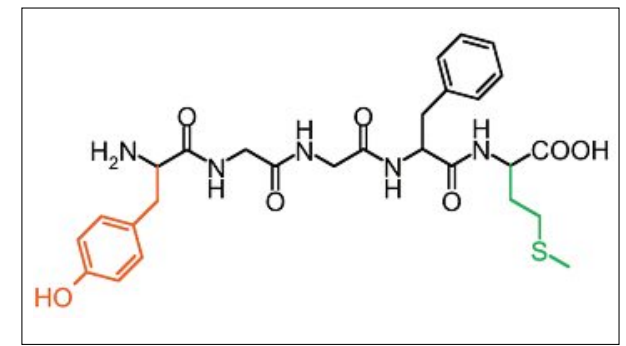

Fig. 7. Methionine enkephalin is a pentapeptide containing methionine and tyrosine residues 


\subsection{Photochemistry}

\subsubsection{Methionine Derivatives and Linear Peptides Containing a Single Met Residue ${ }^{[37,52-54]}$}

Nanosecond laser flash photolysis was used to study the mechanism of sensitized photooxidation of methionine derivatives (N-Ac-Met, N-Ac-Met-OMe, N-AcMet-NH $\mathrm{NH}_{2}$, H-Met-OMe, H-Met-NH $\mathrm{N}_{2}$ ) and simple peptides containing a single Met residue (Met-Gly, Gly-Met, Gly-Gly-Met, Met-Gly-Gly, Gly-Met-Gly). The general reaction scheme (Scheme 5) presents reactions that can lead to the formation of sulfur-centered radical cations.

Depending on its structure and the experimental conditions (concentrations and $\mathrm{pH})$, the $>\mathrm{S}^{\bullet+}$ radical cation can take part in several reactions: deprotonation, decarboxylation, cyclization to $(\mathrm{S} \therefore \mathrm{N})^{+}$radical cationic species having five-membered ring, and a formation of an intermolecular $(\mathrm{S} \therefore \mathrm{S})^{+}$radical cation. Which of these intermediates were found in particular experiments depended on the $\mathrm{pH}$ and on the location of the methionine residue with respect to the terminal functions. The decarboxylation reaction was found to be negligibly small $\left(\Phi_{\mathrm{CO} 2}<0.02\right)$ and could be neglected for all the peptides studied (Scheme 5).

In the case of methionine methyl ester (H-Met-OMe), the methionine amide (HMet- $\mathrm{NH}_{2}$ ), and the peptides containing an N-terminal methionine (Met-Gly, Met-GlyGly), an additional primary photochemical reaction $\left(\mathrm{k}_{\mathrm{NH}}\right)$ was found to occur. It leads to the formation of $(\mathrm{S} \therefore \mathrm{N})^{+}$radical cations even at low $\mathrm{pH}$ (i.e. proton transfer within the radical ion pair $\left[\mathrm{CB}^{\bullet-} \ldots>\mathrm{S}^{\bullet+}\right]$ from the protonated amino group to the $\mathrm{CB}^{\bullet-}$ radical anion, Scheme 6).

It was found for Met-Gly that the decay of its $(\mathrm{S} \therefore \mathrm{N})^{+}$radical cations was multi-ex-

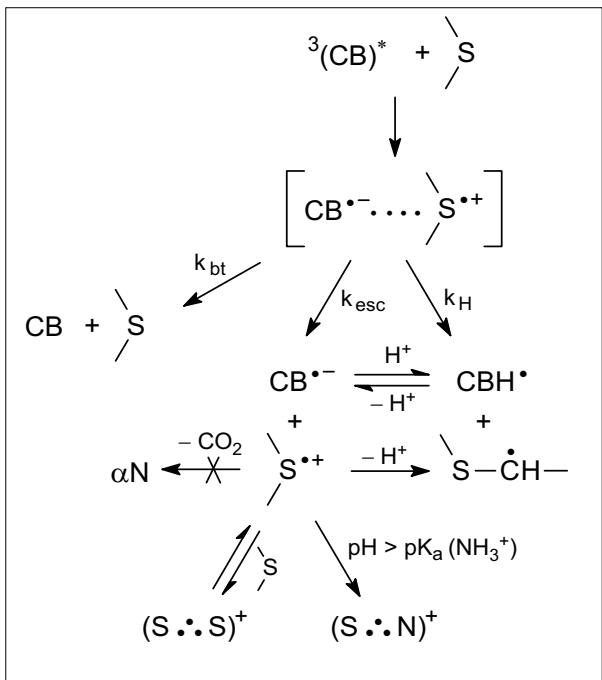

Scheme 5. CB-sensitized photooxidation of methionine derivatives and methioninecontaining peptides in aqueous solution $(\alpha \mathrm{N}-$ represents $\alpha$-aminoalkylradical, and $-\mathrm{S}-\mathrm{C} \cdot \mathrm{H}-$ represents $\alpha$-alkylthioalkyl radical)

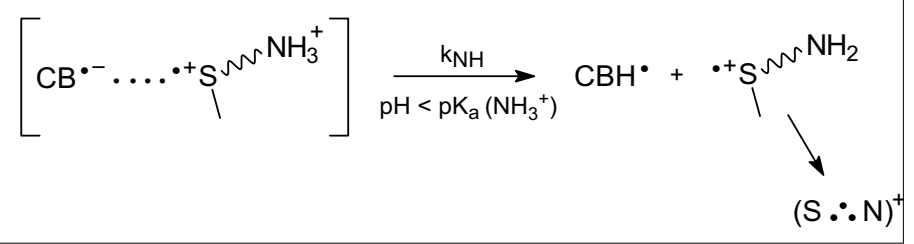

Scheme 6. Formation of $(\mathrm{S} \therefore \mathrm{N})^{+}$radical cations by proton transfer from the protonated amino group to the $\mathrm{CB}^{--}$radical anion

ponential and that the decay varied with $\mathrm{pH}$. This was explained by a reversible reaction of $(\mathrm{S} \therefore \mathrm{N})^{+}$with $\mathrm{OH}^{-[54]}$ in a manner similar to the way $(\mathrm{S} \therefore \mathrm{N})^{+}$radical cations were formed in the pulse radiolysis experiments.

\subsubsection{Linear Peptides Containing Two or More Met Residues[25]}

Competition between formation of intramolecular two-centered, three-electron bonded $(\mathrm{S} \therefore \mathrm{S})^{+}$and $(\mathrm{S} \therefore \mathrm{N})^{+}$was studied for peptides containing two or more methionine units using nanosecond flash photolysis and the procedure described in the experimental part. The following peptides were used in this study: various stereoisomers of methionylmethionine: L-MetL-Met, L-Met-D-Met, D-Met-D-Met, D-MetL-Met, cyclic dipeptide: $c$-(L-Met-L-Met), the tripeptides: L-Met-L-Met-L-Ala, L-MetGly-L-Met, L-Met-L-Met-L-Met, and a tetrapeptide L-Met-Gly-L-Met-L-Met.

This study showed the following results:

i) There is a significant yield of $(\mathrm{S} \therefore \mathrm{N})^{+}$ at low $\mathrm{pH}$ in all cases (this can be explained by the reaction in Scheme 6).

ii) There are relatively high values for the $(\mathrm{S} \therefore \mathrm{N})^{+}$primary quantum yields which are observed for all the peptides at both high and low $\mathrm{pH}$ in comparison with yields for $(\mathrm{S} \therefore \mathrm{S})^{+}$. This indicates that $(\mathrm{S} \therefore \mathrm{N})^{+}$ formation is a competitive reaction to the intramolecular formation of $(\mathrm{S} \therefore \mathrm{S})^{+}$.

iii) There are small but significant differences in the primary quantum yields of $(\mathrm{S} \therefore \mathrm{N})^{+}$and $(\mathrm{S} \therefore \mathrm{S})^{+}$for the mixed (L,D and $\mathrm{D}, \mathrm{L})$ Met-Met stereoisomers in comparison to the D,D and L,L stereoisomers) For $c$-(L-Met-L-Met) the $(\mathrm{S} \therefore \mathrm{N})^{+}$radical cation is not formed.

iv) The decarboxylation reaction can be neglected for all the peptides studied $\left(\Phi_{\mathrm{CO} 2}<0.02\right)$.

\subsubsection{Enkephalins and their Model Peptides ${ }^{[55]}$}

Laser flash photolysis was used to study the mechanism of CB-sensitized photooxidation of methionine-enkephalin (Fig. 7). The results obtained (rate constants for the quenching of $\mathrm{CB}$ triplets and the primary quantum yields for all the observed transients) were compared with those for model peptides such as Tyr-Gly, Tyr-Gly-Gly, PheMet, Tyr-Met, Met-Tyr, and Tyr-Gly-GlyPhe-Leu. It was shown that the primary step of triplet quenching involved an electron transfer and the formation of a radical-ion pair (Scheme 5). This conclusion was supported by the large quenching rate constants (close to the diffusion-controlled limit) and by the presence of radical-ion intermediates: ketyl radicals $\left(\mathrm{CBH}^{\circ}\right)$ and radical anions $\left(\mathrm{CB}^{\circ}\right)$, tyrosyl radicals $\left(\mathrm{TyrO}^{\circ}\right)$, and $(\mathrm{S} \therefore \mathrm{N})^{+}$radical cations in the case of Met-Tyr. When both Met- and Tyr-residues were present in the molecule, e.g. Met-Enk, a competitive photooxidation took place. In particular Tyr and Met residues served as the electron donors. Detailed analysis of the quenching rate constants and the primary quantum yields of all the intermediates demonstrated the existence of an intramolecular electron transfer from the tyrosine residue to the sulfur-centered radical cation $\left(>S^{\bullet+}\right)$ of the Met-residue. This process was shown to take place with $100 \%$ efficiency and was postulated to occur via peptide bonds. A simplified reaction scheme for the CB-sensitized photo-oxidation of MetEnk is presented in Scheme 7.

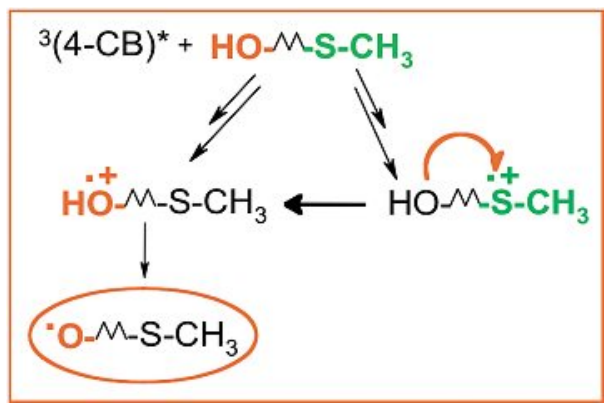

Scheme 7. The mechanism of the CB-sensitized photo-oxidation of MetEnk

\section{Conclusion}

A wealth of knowledge has been accumulated concerning the processes induced by one-electron oxidation of methionine in small peptides thanks to time-resolved techniques. The complex pathways have been elaborated in several cases. Obviously the effects of neighboring groups are of primary importance in this chemistry.

For longer peptides and proteins, radical processes are much more difficult to unravel for several reasons. The characterization of Met-derived radicals in proteins by pulse radiolysis is seldom possible unambiguously, because the absorption bands of the intermediates formed are located in a wavelength range that is very often not characteristic, except for $\mathrm{S} \therefore \mathrm{S}$-bonded radical cations. The participation of neighboring groups cannot be predicted, because of the complexity caused by the three-dimensional structure of proteins. The one-electron 
reduction potential of Met residues varies with the environment, making predictions very hazardous. In addition, a long-range intramolecular electron transfer takes place regenerating the Met-residue and very often leading to oxidation of a tyrosine residue, the final endpoint. Nevertheless the consequences of oxidation of Met residues linked to the oxidative stress have been enlightened in several important pathologies and there is no doubt that the processes demonstrated in small peptides and models do take place in larger systems.

As far as biological implications are concerned, an important point is the nature of final compounds resulting from the various radicals. Up to now, the major oxidized form in proteins is methionine sulfoxide that can result both from a two-electron and one-electron oxidation. MetSO can be reduced further in biological systems by enzymatic processes. However the fate of other final products, if any, and the consequences of one-electron oxidation of Met e.g. in protein synthesis remains unknown.

\section{Acknowledgements}

The support and sponsorship by COST Action CM0603 on 'Free Radicals in Chemical Biology (CHEMBIORADICAL)' are kindly acknowledged.

Received: June 27, 2008

[1] A. L. Lehninger, D. L. Nelson, M. M. Cox, 'Principles of Biochemistry', Worth, New York, version 2.

[2] A. Varshavsky, Proc. Natl. Acad. Sci. USA 1996, 93, 12142

[3] W. Vogt, Free Radic. Biol. Med. 1995, 18, 93.

[4] C. Schöneich, Biochim. Biophys. Acta 2005, 1703,111

[5] D. B. Oiena, J. Moskovitz, Current Topics in Developmental Biology 2007, 80, 93.

[6] R. L. Levine, B. S. Berlett, J. Moskovitz, L. Mosoni, E. R. Stadtman, Mech. Ageing Development 1999, 107, 323.

[7] D. A. Butterfield, Chem. Res. Toxicol. 1997, 10, 495.

[8] D. A. Butterfield, D. Kimball-Boyd, Biochim. Biophys. Acta 2005, 1703, 149.

[9] K. Hensley, J. M. Carney, M. P. Matson, M. Aksenova, M. Harris, J. M. Wu, R. A. Floyd, D. A. Butterfield, Proc. Natl. Acad. Sci. USA 1994, 91, 3270.

[10] I. Dalle-Donne, R. Rossi, D. Giustarini, N. Gagliano, P. Di Simplicio, R. Colombo, A. Milzani, Free Radic. Biol. Med. 2002, 32, 927.

[11] C. B. Glasser, G. Yamin, V. N. Uversky, A. L. Fink, Biochim. Biophys. Acta 2005 , $1703,157$.

[12] D. Perrin, W. H. Koppenol, Arch. Biochem. Biophys. 2000, 377, 266.

[13] W. A. Pryor, X. Jin, G. L. Squadrito, Proc. Natl. Acad. Sci. USA 1994, 91, 11173.

[14] K. Bobrowski, B. Marciniak, G. L. Hug, J. Am. Chem. Soc. 1992, 114, 10279.

[15] K.-O. Hiller, K.-D. Asmus, Int. J. Radiat. Biol. 1981, 40, 583.
[16] J. Mönig, M. Göbl, K.-D. Asmus, J. Chem. Soc., Perkin Trans. 1985, 2, 647.

[17] K.-O. Hiller, K.-D. Asmus, Int. J. Radiat. Biol. Relat. Stud. Phys., Chem. Med. 1981 40, 597.

[18] K.-O. Hiller, B. Masloch, M. Göbl, K. D. Asmus, J. Am. Chem. Soc. 1981, 103, 2734.

[19] R. S. Glass, 'Neighboring group participation: General principles and application to sulfur-centered reactive species', Ed. C. Chatgilialoglu, K.-D. Asmus, Plenum Press: New York, 1990, Vol. 97, pp 213-224.

[20] T. Clark, in 'Sulfur-centered reactive intermediates in Chemistry and Biology', Ed. C. Chatgilialoglu, K.-D. Asmus, NATO-ASI Studies, Plenum Press New York, 1990, 197, pp. 13-18.

[21] K.-D. Asmus, in 'Radiation Chemistry, present status and future trends', Ed. C. D. Jonah, B. S. M. Rao Elsevier, Amsterdam, 2001, pp. 341-393.

[22] K.-D. Asmus, M. Bonifacic, 'Sulfurcentered reactive intermediates as studied by radiation chemical and complementary techniques', Ed. Z. B. Alfassi, John Wiley\&Sons Ltd., Chichester, 1999, pp. 141-191.

[23] K. Bobrowski, D. Pogocki, C. Schöneich, J. Phys. Chem. A 1998, 102, 10512; K. Bobrowski, G. L. Hug, B. Marciniak, B. L. Miller, C. Schöneich, J. Am. Chem. Soc. 1997, 119, 8000; K. Bobrowski, D. Pogocki, C. Schöneich, J. Phys. Chem. 1993, 97, 13677; S. Mahling, K.-D. Asmus, R. S. Glass, M. Hojjatie, G. S. Wilson, J. Org. Chem. 1987, 52, 3717; K.-D. Asmus, M. Göbl, K.-O. Hiller, S. Mahling, J. Mönig, $J$ Chem. Soc., Perkin Trans. 2 1985, 641.

[24] P. Brunelle, C. Schoneich, A. Rauk, Can. J. Chem. 2006, 84, 893; P. Brunelle, A. Rauk, J. Phys. Chem. A 2004, 108, 11032 I. Fourré, J. Bergés, J. Phys. Chem. A 2004, 108, 898; D. Pogocki, K. Serdiuk, C. Schoneich, J. Phys. Chem. A 2003, 107 , 7032; D. Pogocki, C. Schöneich, J. Org. Chem. 2002, 67, 1526.

[25] G. L. Hug, K. Bobrowski, H. Kozubek, B. Marciniak, Photochem. Photobiol. 2000, 72, 1; K. Bobrowski, C. Schöneich, Radiat. Phys. Chem. 1996, 47, 507; B. Marciniak, C. Schöneich, F. Zhao, K. P. Madden, K Bobrowski, J. Am. Chem. Soc. 1994, 116 , 4641; K. Bobrowski, J. Holcman, J. Phys. Chem. 1989, 93, 6381; K. Bobrowski, J. Holcman, Int. J. Radiat. Biol. Relat. Stud. Phys., Chem. Med. 1987, 52, 139.

[26] G. L. Hug, K. Bobrowski, H. Kozubek, B Marciniak, J. Phys. Chem. 1995, 99, 13560.

[27] C. von Sonntag, 'The Chemical Basis of Radiation Biology', Taylor and Francis, New York, 1987.

[28] E. Janata, R. H. Schuler, J. Phys. Chem. 1982, 86, 2078.

[29] G. V. Buxton, C. L. Greenstock, W. P. Helman, A. B. Ross, J. Phys. Chem. Ref. Data 1988, 17, 513.

[30] R. H. Schuler, A. L. Hartzell, B. Behar, J. Phys. Chem. 1981, 85, 192.

[31] S. Karolczak, 'Pulse radiolysis - experimental features', Ed. J. Mayer, Polish Scientific Publishers, PWN, Warszawa, 1999, pp. 11-37.

[32] K.-D. Asmus, 'Pulse radiolysis methodology', 1984, Vol. 105, p 167.
[33] K.-D. Asmus, 'Application of conductivity techniques in pulse radiolysis', Ed. G. E. Adams, E. M. Fielden, B. D. Mitchel, The Institute of Physics, Willey, New York, 1975, pp. 58 .

[34] K. Bobrowski, Nukleonika 2005, 50 (Supplement 3), S67; G. L. Hug, Y. Wang, C. Schöneich, P.-Y. Jiang, R. W. Fessenden, Radiat. Phys. Chem. 1999, 54, 559.

[35] V. Favaudon, H. Tourbez, C. Houée-Levin, J. M. Lhoste, Biochemistry 1990, 29 , 10978.

[36] B. Marciniak, G. L. Hug, K. Bobrowski, H Kozubek, J. Phys. Chem. 1995, 99, 13560.

[37] K. Bobrowski, B. Marciniak, G. L. Hug, $J$. Photochem. Photobiol. A: Chem. 1994, 81 , 159.

[38] P. Filipiak, J. Bartoszewicz, G. L. Hug, H. Kozubek, B. Marciniak, J. Photochem. Photobiol. A: Chem. 2007, 191, 167.

[39] 'Metody badania mechanizmów reakcji fotochemicznych' (Methods for studying mechanisms of photochemical reactions), Ed. B. Marciniak, Wydawnictwo Naukowe UAM, Poznan, 1999, chap. 1.

[40] M. D. Thomas, G. L. Hug, Comput. Chem. (Oxford) 1998, 22, 491.

[41] C. Schöneich, D. Pogocki, G. L. Hug, K. Bobrowski, J. Am. Chem. Soc. 2003, 125 , 13700.

[42] K. Bobrowski, G. L. Hug, D. Pogocki, B. Marciniak, C. Schöneich, J. Am. Chem. Soc. 2007, 129, 9236.

[43] K. Bobrowski, G. L. Hug, D. Pogocki, B. Marciniak, C. Schöneich, J. Phys. Chem. B 2007, 111, 9608; G. L. Hug, K. Bobrowski, D. Pogocki, G. Hörner, B. Marciniak, ChemPhysChem 2007, 8, 2202.

[44] T. Nauser, M. Jacoby, W. H. Koppenol, T. C. Squier, C. Schöneich, Chem. Commun. 2005, 587.

[45] C. Sicard-Roselli, C. Houée-Levin, 'Radiation chemistry of proteins', in 'Radiation chemistry: present status and future prospects', Ed. C. Jonah, B. M. Rao, Elsevier, 2001, pp. 553-584.

[46] W. A. Prütz, J. Butler, E. J. Land, A. J. Swallow, Biochem. Biophys. Res. Commun. 1980, $96,408$.

[47] V. Kadlcik, C. Sicard-Roselli, M. Kodicek, C. Houée-Levin, Free Rad. Biol. Med. 2004, 37, 881.

[48] P. Wardman, J. Phys. Chem. Ref. Data 1989, 18, 1637.

[49] C. Sicard-Roselli, S. Lemaire, J.-P. Jacquot, V. Favaudon, C. Marchand, C. HouéeLevin, Eur. J. Biochem. 2004, 271, 3481.

[50] O. Mozziconnacci, J. Mirkowski, F. Rusconi, P. Pernot, K. Bobrowski, C. Houée-Levin, Free Radic. Biol. Med. 2007, 43, 229.

[51] T. Nauser, M. Jacoby, W. H. Koppenol, T. C. Squier, C. Schöneich, Chem. Commun. 2005, 587.

[52] G. L. Hug, K. Bobrowski, H. Kozubek, B. Marciniak, Nukleonika 2000, 45, 63.

[53] G. L. Hug, K. Bobrowski, H. Kozubek, B. Marciniak, Photochem. Photobiol. 1998 $68,785$.

[54] G. L. Hug, B. Marciniak, K. Bobrowski, J. Phys. Chem. 1996, 100, 14914.

[55] A. Wojcik, A. Lukaszewicz, O. Brede, B. Marciniak, J. Photochem. Photobiol. A. Chem. 2008, 198, 111. 